\title{
Comment on Lee et al.: Incidence of second hip fracture and compliant use of bisphosphonate
}

\author{
Y. Zhu $\cdot$ W. Chen $\cdot$ Y. Zhang
}

Received: 29 November 2013 / Accepted: 21 April 2014 / Published online: 13 May 2014

(C) International Osteoporosis Foundation and National Osteoporosis Foundation 2014

Dear Editor,

On reading the article "Incidence of second hip fracture and compliant use of bisphosphonate" by Lee et al. [1], recently published in Osteoporosis International, we came across an obvious error.

Regarding the efficacy of bisphosphonate for the prevention of second hip fracture, the authors cited an article entitled "The rate of contralateral proximal femoral fracture following closed reduction and percutaneous pinning compared with arthroplasty for the treatment of femoral neck fractures" by Souder et al. [2] and stated that "one study reported a protective effect of bisphosphonate for the prevention of a second hip fracture".

However, when we read that article [2] we found that the use of bisphosphonate was an adverse rather than a protective factor for prevention of second hip fracture. The data were presented as follows [2]:

\begin{tabular}{llll}
\hline Bisphosphonates & $\begin{array}{c}\text { No second hip } \\
\text { fracture } \\
(N=1,089)\end{array}$ & $\begin{array}{c}\text { Second hip } \\
\text { fracture } \\
(N=88)\end{array}$ & P-value \\
Yes (Actonel, & $150(88.76 \%)$ & $19(11.24 \%)$ & $\mathbf{0 . 0 4 4 3}^{1}$ \\
$\quad$ Alendro, Fosamax) & $939(93.15 \%)$ & $69(6.85 \%)$ & \\
No & & \\
\hline
\end{tabular}

${ }^{1}$ Chi-square test

The error described herein has now been corrected in an erratum that can be found at DOI 10.1007/00198-014-2731-4.

Y. Zhu $\cdot$ W. Chen $\cdot$ Y. Zhang $(\bowtie)$

Department of Orthopedics, The 3rd Hospital, Hebei Medical

University, NO. 139 Ziqiang Road, Shijiazhuang 050051, People's

Republic of China

e-mail: dryzzhang@126.com
We hope that pointing out this error will contribute to further understanding of the use of bisphosphonates in preventing second hip fracture and help to prevent tragedies in elderly patients who have suffered their first hip fracture.

\section{References}

1. Lee Y-K, Ha Y-C, Yoon B-H, Koo K-H (2013) Incidence of second hip fracture and compliant use of bisphosphonate. Osteoporos Int 24: 2099-2104. doi:10.1007/s00198-012-2250-0

2. Souder CD, Brennan ML, Brennan KL, Song J, Williams J, Chaput C (2012) The rate of contralateral proximal femoral fracture following closed reduction and percutaneous pinning compared with arthroplasty for the treatment of femoral neck fractures. J Bone Joint Surg 94(5):418-425 